\title{
The impact of histological types on the efficacy of angiogenesis inhibitors in the treatment of advanced NSCLC: a meta-analysis of randomized controlled trials
}

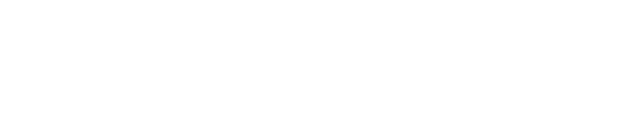

\author{
Jian Zhangl,* \\ Jie $\mathrm{Liu}^{2, *}$ \\ Huiguo Chen' \\ Weibin $\mathrm{Wu}^{\prime}$ \\ Xiaojun $\mathrm{Li}^{\prime}$ \\ Yonghui $\mathrm{Wu}^{\prime}$ \\ Kai Zhang' \\ Lijia Gu'
}

'Department of Thoracic Surgery, 2Department of Pharmacy, The Third Affiliated Hospital of Sun Yat-sen University, Guangzhou, Guangdong Province, People's Republic of China

*These authors contributed equally to this work
Correspondence: Lijia Gu Department of Thoracic Surgery, The Third Affiliated Hospital of Sun Yat-sen University, No 600, Tianhe Road, Tianhe District, Guangzhou, Guangdong Province, 510000, People's Republic of China Tel +867532829258 Email gulijia2015@I63.com
Purpose: We aimed at assessing the overall efficacy of angiogenesis inhibitor (AI)-containing regimens in the treatment of advanced non-small-cell lung cancer (NSCLC) according to histological types.

Methods: Studies from PubMed and Web of Science, and abstracts presented at American Society of Clinical Oncology (ASCO) meeting up to October 31, 2014 were searched to identify relevant studies. Eligible studies included prospective randomized controlled trials (RCTs) evaluating AIs in advanced NSCLC with survival data according to patients' histologies. The endpoints were overall survival (OS) and progression-free survival (PFS). Statistical analyses were conducted by using either random effects or fixed effect models according to the heterogeneity of included studies.

Results: A total of 10,035 patients with advanced NSCLC from 13 RCTs were identified for analysis. The pooled results demonstrated that AI-containing regimens significantly improved the PFS (HR, 0.84, 95\% confidence interval (CI): 0.78-0.91, $P<0.001)$ and OS (HR, 0.92, 95\% CI: $0.85-0.99, P=0.017)$ in lung adenocarcinoma when compared to non-AI-containing regimens. Additionally, there was a significantly improved PFS (HR, 0.87, 95\% CI: 0.77-0.98, $P=0.027$ ) for AI-containing regimens in squamous cell lung carcinoma, but it did not translated into OS benefit (HR, 1.02, 95\% CI: $0.92-1.15, P=0.68$ ). For NSCLC patients with other histological types, the use of AIs did not significantly improve PFS (HR, $0.90,95 \%$ CI: $0.75-1.09, P=0.27$ ) and OS (HR, 0.90, 95\% CI: 0.76-1.08, $P=0.19$ ).

Conclusion: The findings of this study suggest that the addition of AIs to the treatment therapies for patients with lung adenocarcinoma offers improved survival benefits. Prospective clinical trials investigating the role of AIs in this setting are recommended.

Keywords: non-small-cell lung cancer, histological types, randomized controlled trials, angiogenesis inhibitors, meta-analysis

\section{Introduction}

Lung cancer is the leading cause of cancer-related mortality, with an estimated 1.4 million deaths each year. ${ }^{1}$ Non-small-cell lung cancer (NSCLC) accounts for $85 \%$ of the cases. Most of the NSCLC patients have advanced disease at diagnosis. For these patients, platinum-based doublet therapy is the standard of care. ${ }^{2}$ Regardless of the emergence of new cytotoxic agents, chemotherapy provides only marginal benefit in overall survival (OS). Clearly, novel therapeutic approaches to improve outcomes for patients with NSCLC are urgently needed. ${ }^{3}$

Angiogenesis, the process of new blood vessel formation, is critical for tumor progression, invasion, and metastasis in solid tumors. ${ }^{46}$ The vascular endothelial 
growth factor (VEGF) pathway has been the most well studied. ${ }^{7}$ Currently, bevacizumab is the only approved antiangiogenic agent for NSCLC patients when added to first-line carboplatin/paclitaxel chemotherapy. ${ }^{8-10}$ More recently, many new antiangiogenic agents targeting plateletderived growth factor (PDGF) and fibroblast growth factor pathways are under clinical evaluation in NSCLC. ${ }^{11-17}$ In fact, a recent meta-analysis has demonstrated that the use of angiogenesis inhibitors (AIs) significantly improved OS and progression-free survival (PFS) in comparison with non-AI-containing therapies. ${ }^{18}$ However, NSCLC contains several different histological subtypes, and the biological behavior of each cell type appears to be different, which might affect the efficacy of AIs in different histological types. As a result, we performed this meta-analysis based on histologies to identify patients who will most likely benefit from AI-combining therapies.

\section{Materials and methods Selection of studies}

We searched PubMed (data from January 2000 to October 2014), Embase (data from January 2000 to October 2014), and the Cochrane Library electronic databases. The search criteria included only randomized controlled trials (RCTs) published in the English language, and the keywords "bevacizumab", "avastin", “aflibercept", "VEGFR-TKIs", "sorafenib", "nexavar”, “sunitinib”, "sutent”, "SU1248”, "vandetanib”, “caprelsa”, “ZD6474”, “axitinib”, "pazopanib”, "votrient”, “GW786034”, "regorafenib”, “apatinib”, "ramucirumab”, "nintedanib", "BIBF1120", "thalidomide", "lenalidomide”, "motesanib", "angiogenesis inhibitors", "randomized", and "non-small-cell lung cancer". We also searched abstracts and virtual meeting presentations from the American Society of Clinical Oncology (http://www.asco.org/ASCO) conferences that took place between January 2004 and June 2014. Each publication was reviewed and in case of duplicate publication only the most complete, recent, and updated report of the clinical trial was included in the meta-analysis.

\section{Data extraction and clinical end point}

Data extraction was conducted independently by two investigators according to the Preferred Reporting Items for Systematic Reviews and Meta-analysis statement (see checklist Table S1 $)^{19}$ and any discrepancy between the reviewers was resolved by consensus. For each study, the following information was extracted: first author's name, year of publication, trial phase, number of enrolled patients, treatment arms, age, primary end points, and median follow-up.
Phase I trials and single-group Phase II trials were omitted from analysis because of lack of controls. Trials that met the following criteria were included in our analysis: 1) prospective RCTs comparing AI-containing regimen to AIfree regimens as any line treatments in advanced NSCLC;2) trials involving patients who were pathologically confirmed to have NSCLC; and 3) trials having sufficient survival data according to histological types for extraction. If multiple publications of the same trial were retrieved or if there was a case mix between publications, only the most recent publication (and the most informative) was included. The quality of reports of clinical trials was assessed and calculated using the 5-item Jadad scale including randomization, double-blinding, and withdrawals as described previously. ${ }^{20}$

\section{Data analysis}

The analysis was undertaken on an intention-to-treat basis: patients were analyzed according to treatment allocated, irrespective of whether they received that treatment. The outcomes used were 1) OS, defined as the time from random assignment to death from any cause, censoring patients who had not died at the date last known alive; 2) PFS, defined as the time from random assignment to first documented progression.

Statistical analysis of the overall hazard ratio (HR) for OS and PFS was calculated using Version 2 of the Comprehensive Meta analysis program (Biostat, Englewood, NJ, USA). A statistical test with a $P$-value less than 0.05 was considered significant. HR $>1$ reflected more deaths or progression in AI-containing regimens group, and vice versa. Between-study heterogeneity was estimated using the $\chi^{2}$-based $Q$ statistic. $^{21}$ The $I^{2}$ statistic was also calculated to evaluate the extent of variability attributable to statistical heterogeneity between trials. Heterogeneity was considered statistically significant when $P_{\text {heterogeneity }}<0.05$ or $P>50 \%$. If heterogeneity existed, data were analyzed using a random effects model. In the absence of heterogeneity, a fixed-effects model was used. The presence of publication bias was evaluated by using the Begg and Egger tests. ${ }^{22}$ All $P$-values were two sided. All confidence intervals (CIs) had a two-sided probability coverage of $95 \%$.

\section{Results}

\section{Search results}

A total of 320 potentially relevant studies were retrieved electronically, 307 of which were excluded for the reasons shown in Figure 1. Thirteen published RCTs with subgroup analysis assessing the efficacy of AIs in NSCLC according to different histologies were included in the 


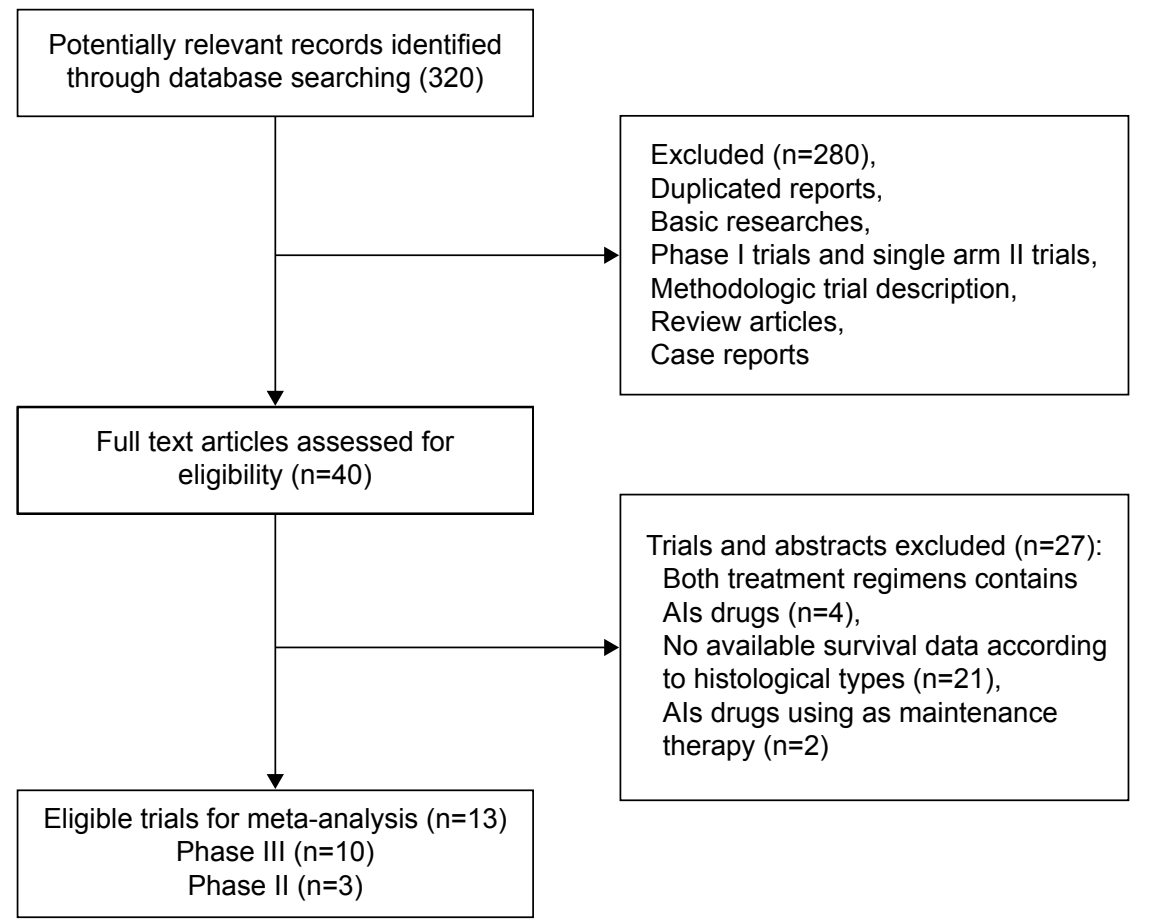

Figure I Studies eligible for inclusion in the meta-analysis.

meta-analysis. ${ }^{15,23-34}$ The baseline characteristics of each trial are listed in Table 1. A total of 10,035 patients were available. Six trials were performed in first-line settings, and seven in second-line. According to the inclusion criteria of each trial, patients were required to have adequate renal, hepatic, and hematologic function. The quality of each study was roughly assessed according to the Jadad scale. Ten trials had Jadad score of 5,,$^{15,24,25,27-32,34}$ and three trials had Jadad score of 3.23,26,33

\section{Overall survival}

For patients with lung adenocarcinoma, seven of the 13 trials with a total of 4,457 patients reported OS data. The pooled results demonstrated that the use of AIs significantly improve OS in comparison with non-AI-containing therapies (HR, 0.92, 95\% CI: $0.85-0.99, P=0.017$, Figure 2 and Table 2 ) using a fixed-effects model $\left(I^{2}=0 \%\right)$. A total of 1,796 squamous cell cancer (SCC) patients from nine trials reported OS data, and the pooled results found that AI-containing regimens did not improve OS in comparison with non-AIcontaining regimens (HR, $1.02,95 \% \mathrm{CI}: 0.92-1.15, P=0.68$, Figure 2 and Table 2$)$ using a fixed-effects model $\left(I^{2}=24.3 \%\right)$. Additionally, a nonsignificantly improved OS was observed in NSCLC patients with other histologies who were treated with AI-containing therapies (HR, 0.90, 95\% CI: 0.76-1.08, $P=0.19$, Figure 2 and Table 2 ). We then performed subgroup analysis according to treatment line. Our results showed that the use of AIs as second-line therapy in adenocarcinoma significantly improved OS (HR, 0.93, 95\% CI: 0.86-1.00, $P=0.05$ ), while only one trial using AIs as first-line therapy in adenocarcinoma was included for analysis, and a tendency to improve OS was also observed (HR, 0.88, 95\% CI: $0.75-1.03, P=0.11$ ). For SCC patients, the use of AIs as second-line therapy seemed to improve OS (HR, 0.97, 95\% CI: $0.86-1.10, P=0.66)$. However, the use of AIs as first-line therapy in these patients tended to decrease OS (HR, 1.25, 95\% CI: $0.97-1.60, P=0.08$ ).

\section{Progression-free survival}

A total of 3,692 lung adenocarcinoma and 1,354 SCC patients were included for analysis. The pooled HR for PFS demonstrated that AI-containing therapies significantly improve PFS in lung adenocarcinoma (HR, 0.84, 95\% CI: 0.78-0.91, $P<0.001$, Figure 3 and Table 2 ) and SCC (HR, $0.87,95 \%$ CI: $0.77-0.98, P=0.027$, Figure 2 and Table 2 ), compared with non-AIs containing therapy. There was moderate heterogeneity between trials $\left(I^{2}=43.9 \%\right.$ and $\left.46.2 \%\right)$, and the pooled HR for PFS was performed by using fixed-effects model. For patients with other histologies, the pooled results did not significantly improve PFS when compared to non-AIcontaining regimens (HR, $0.90 ; 95 \% \mathrm{CI}: 0.75-1.09, P=0.27$, Figure 2 and Table 2). 
Table I Baseline characteristic of included I3 trials for analysis

\begin{tabular}{|c|c|c|c|c|c|c|c|c|c|}
\hline \multirow[t]{2}{*}{ Study } & \multirow{2}{*}{$\begin{array}{l}\text { Total } \\
\text { patients }\end{array}$} & \multirow{2}{*}{$\begin{array}{l}\text { Treatment } \\
\text { line }\end{array}$} & \multicolumn{3}{|l|}{ Histologies } & \multirow[t]{2}{*}{ Treatment regimens } & \multirow{2}{*}{$\begin{array}{l}\text { Primary } \\
\text { endpoint }\end{array}$} & \multirow{2}{*}{$\begin{array}{l}\text { Median follow- } \\
\text { up }(\mathrm{mo})\end{array}$} & \multirow{2}{*}{$\begin{array}{l}\text { Jadad } \\
\text { score }\end{array}$} \\
\hline & & & Adenocarcinoma & Squamous & Others & & & & \\
\hline \multirow[t]{2}{*}{ Heymach et al ${ }^{25}$} & 108 & First line & 59 & 26 & 23 & $\begin{array}{l}\text { Vandetanib } 300 \text { mg qd } \\
\text { po + PTX + CBP }\end{array}$ & PFS & NR & 5 \\
\hline & & & & & & Placebo + PTX + CBP & & & \\
\hline Natale et $\mathrm{a}^{27}$ & 168 & Second line & 98 & 38 & 32 & $\begin{array}{l}\text { Vandetanib } 300 \mathrm{mg} \text { qd po } \\
\text { gefitinib } 250 \mathrm{mg} \text { qd po }\end{array}$ & PFS & NR & 5 \\
\hline \multirow[t]{4}{*}{ Reck et al ${ }^{29}$} & $\mathrm{I}, 043$ & First line & 876 & 0 & 167 & $\begin{array}{l}\text { Bev } 7.5 \text { mg/kg + DDP + } \\
\text { GEM }\end{array}$ & PFS & NR & 5 \\
\hline & & & & & & Bev 15 mg/kg + DDP + & & & \\
\hline & & & & & & GEM & & & \\
\hline & & & & & & Placebo + DDP + GEM & & & \\
\hline \multirow[t]{2}{*}{ Herbst et a $\left.\right|^{34}$} & I,39| & Second line & 829 & 344 & 218 & $\begin{array}{l}\text { Vandetanib } 100 \mathrm{mg} q d \\
\text { po + Doc }\end{array}$ & PFS & 12.8 & 5 \\
\hline & & & & & & Placebo + Doc & & & \\
\hline \multirow[t]{2}{*}{ Hoang et $\mathrm{a}^{26}$} & 546 & First line & 202 & 191 & 153 & $\begin{array}{l}\text { Thalidomide } 200 \mathrm{mg} q \mathrm{~d}+ \\
\text { PTX + CBP + RT }\end{array}$ & OS & 61.8 & 3 \\
\hline & & & & & & $\mathrm{PTX}+\mathrm{CBP}+\mathrm{RT}$ & & & \\
\hline \multirow[t]{2}{*}{ Scagliotti et al ${ }^{14}$} & 926 & First line & 534 & 223 & 169 & $\begin{array}{l}\text { Sorafenib } 400 \mathrm{mg} \text { bid } \\
\text { po + CBP + PTX }\end{array}$ & OS & NR & 5 \\
\hline & & & & & & Placebo + PTX + CBP & & & \\
\hline \multirow[t]{2}{*}{ de Boer et $\mathrm{al}^{24}$} & 534 & Second line & 336 & 114 & 84 & $\begin{array}{l}\text { Vandetanib } 100 \mathrm{mg} \text { qd } \\
\text { po + pemetrexed }\end{array}$ & PFS & NR & 5 \\
\hline & & & & & & Placebo + pemetrexed & & & \\
\hline \multirow[t]{2}{*}{ Herbst et $\mathrm{al}^{33}$} & 636 & Second line & 477 & 28 & 131 & Bev $15 \mathrm{mg} / \mathrm{kg}$ + erlotinib & OS & 19 & 3 \\
\hline & & & & & & Erlotinib $150 \mathrm{mg}$ qd po & & & \\
\hline \multirow[t]{2}{*}{ Natale et $\mathrm{a}^{28}$} & $\mathrm{I}, 240$ & Second line & 741 & 272 & 227 & $\begin{array}{l}\text { Vandetanib } 300 \mathrm{mg} \text { qd } \\
\text { po + erlotinib }\end{array}$ & PFS & NR & 5 \\
\hline & & & & & & Placebo + erlotinib & & & \\
\hline \multirow[t]{2}{*}{ Scagliotti et a $\left.\right|^{31}$} & 960 & Second line & 506 & 270 & 184 & $\begin{array}{l}\text { Sunitinib } 17.5 \mathrm{mg} \text { qd } \\
\text { po + erlotinib }\end{array}$ & OS & 21.3 & 5 \\
\hline & & & & & & Placebo + erlotinib qd po & & & \\
\hline \multirow[t]{2}{*}{ Scagliotti et $\mathrm{al}^{32}$} & 1,090 & First line & 890 & 0 & 200 & $\begin{array}{l}\text { Motesanib I25 mg qd } \\
\text { po + CBP + PTX }\end{array}$ & OS & II & 5 \\
\hline & & & & & & Placebo + CBP + PTX & & & \\
\hline \multirow[t]{3}{*}{ Garon et al' ${ }^{15}$} & 1,253 & Second line & 912 & 328 & 13 & Ramucirumab $10 \mathrm{mg} / \mathrm{kg}$ & OS & 9.5 & 5 \\
\hline & & & & & & + Doc & & & \\
\hline & & & & & & Placebo + Doc & & & \\
\hline \multirow[t]{3}{*}{ Doebele et $\mathrm{a}^{23}$} & 140 & First line & 122 & 0 & 18 & Ramucirumab + & PFS & NR & 3 \\
\hline & & & & & & Pemetrexed + platinum & & & \\
\hline & & & & & & Pemetrexed + platinum & & & \\
\hline
\end{tabular}

Abbreviations: PTX, paclitaxel; CBP, carboplatin; DDP, cisplatin; GEM, gemcitabine; Doc, docetaxel; RT, radiotherapy; Bev, bevacizumab; PFS, progression-free survival; OS, overall survival; NR, not reported.

\section{Publication bias}

Begg's funnel plot and Egger's test were performed to assess the publication bias of literatures. Begg's funnel plots did not reveal any evidence of obvious asymmetry for PFS (adenocarcinoma: $P=0.46$, SCC: $P=0.13$, and other histologies: $P=0.80$, respectively) and $\mathrm{OS}$ (adenocarcinoma: $P=0.76$, SCC: $P=0.12$, and other histologies: $P=0.06$ ). Then, Egger's test was used to provide statistical evidence of funnel plot symmetry. The results still did not suggest any evidence of publication bias for PFS (adenocarcinoma: $P=0.27$, SCC:
$P=0.13$, and other histologies: $P=0.56$, respectively) and $\mathrm{OS}$ (adenocarcinoma: $P=0.94$ and SCC: $P=0.33$ respectively), but not for OS in patients with other histologies $(P=0.02)$. The difference in the results obtained from the two methods might be due to a greater statistical power of the regression methods. $^{35}$

\section{Discussion}

NSCLC includes various histological types; SCC and adenocarcinoma are the most common. There are several differences 


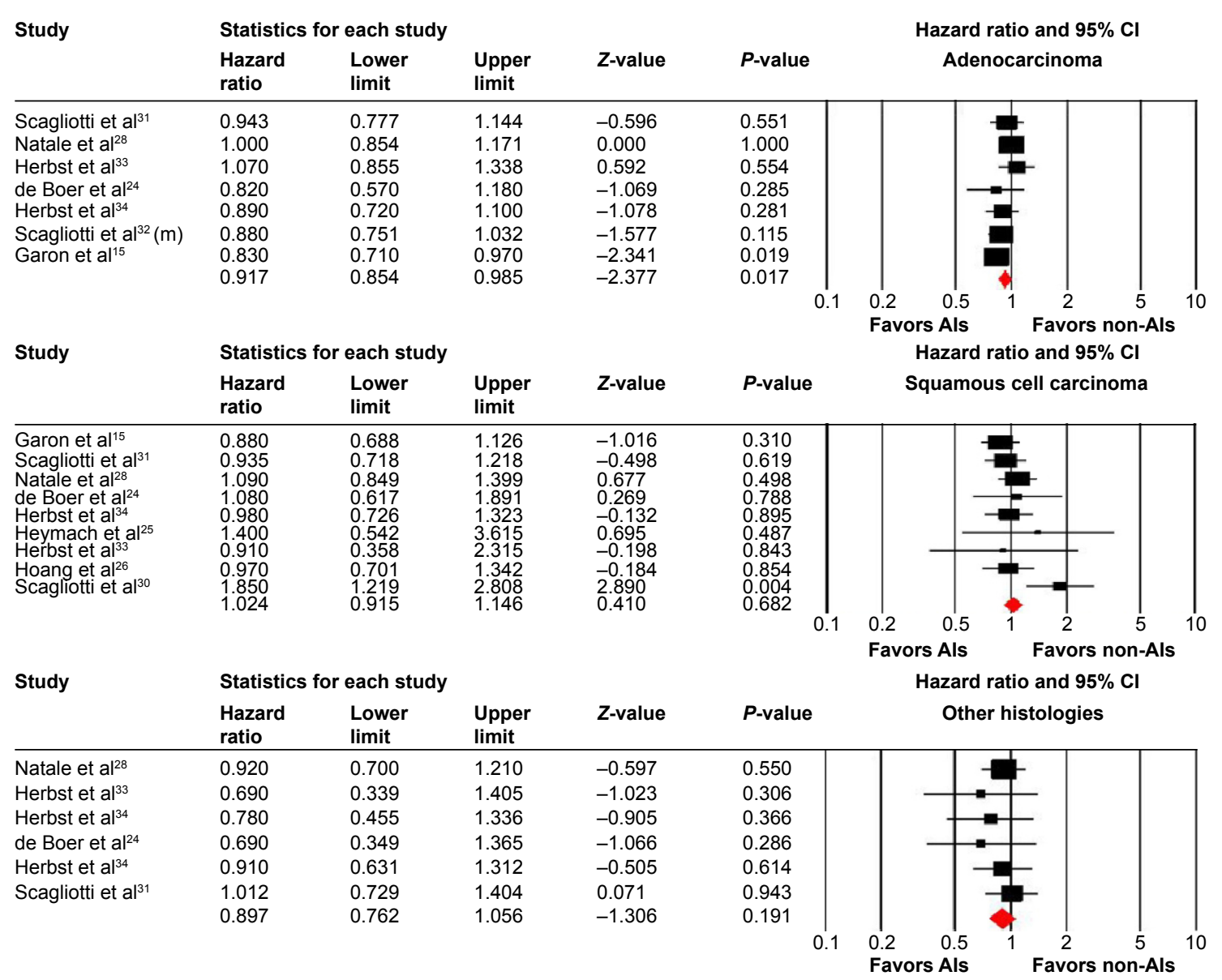

Figure 2 Fixed-effects model of $\mathrm{HR}(95 \% \mathrm{Cl})$ of OS associated with Al-containing regimens versus non-Al-containing regimens.

Abbreviations: $\mathrm{HR}$, hazard ratio; $\mathrm{Cl}$, confidence interval; OS, overall survival; Als, angiogenesis inhibitors.

in the clinical behavior of the histological types. Adenocarcinoma has a relatively higher possibility of developing distant metastases without local progression in NSCLC patients treated with definitive radiotherapy. A Japanese randomized Phase III trial of adjuvant chemotherapy with uracil-tegafur for completely resected pathological stage I NSCLC showed a survival benefit for patients with adenocarcinoma; however,

Table 2 Comparison of primary outcomes for therapies with or without angiogenesis inhibitors according to histologies

\begin{tabular}{clllll}
\hline Groups & Trials (n) & Patients (n) & $\boldsymbol{I}^{\mathbf{2}}(\%)$ & HR (95\%) & $\boldsymbol{P}$ \\
\hline SCC & & & & & \\
OS & 9 & 1,796 & 24.3 & $1.02(0.92-1.15)$ & 0.68 \\
PFS & 6 & 1,354 & 46.2 & $0.87(0.77-0.98)$ & 0.027 \\
Adenocarcinoma & & & & \\
$\quad$ OS 7 & 4,457 & 0 & $0.92(0.85-0.99)$ & 0.017 \\
PFS 8 & 3,692 & 43.9 & $0.84(0.78-0.91)$ & $<0.001$ \\
Others & & & & & \\
OS & 5 & 860 & 0 & $0.90(0.76-1.08)$ & 0.19 \\
PFS & 4 & 594 & 0 & $0.90(0.75-1.09)$ & 0.27 \\
\hline
\end{tabular}

Note: $l^{2} \geq 50 \%$ suggests high heterogeneity across studies.

Abbreviations: SCC, squamous-cell carcinoma; OS, overall survival; PFS, progression-free survival; HR, hazard ratio. there was no benefit for patients with SCC. ${ }^{36,37}$ Similarly, a Phase III trial in regionally advanced, unresectable NSCLC to test whether chemotherapy followed by radiotherapy resulted in survival superior to either hyperfractionated radiotherapy alone or standard radiotherapy alone revealed a survival benefit in patients with nonsquamous cell carcinoma, whereas no benefit was recognized in those with SCC. These data suggest that the histological subtype is a very important factor to establish the treatment strategy for NSCLC. We thus performed this meta-analysis according to histologies identify patients who will most likely benefit from AI-combining therapies.

To the best of our knowledge, this study is the first meta-analysis with a focus on investigating the impact of histological types on the efficacy of AIs in advanced NSCLC. This study includes 13 RCTs incorporating 10,035 patients. The pooled results confirm that AI-containing regimens significantly improve PFS and OS in patients with lung adenocarcinoma compared to non-AI-containing regimens. For patients with squamous cell lung carcinoma, the use of AIs significantly improves PFS, but not OS. Additionally, 


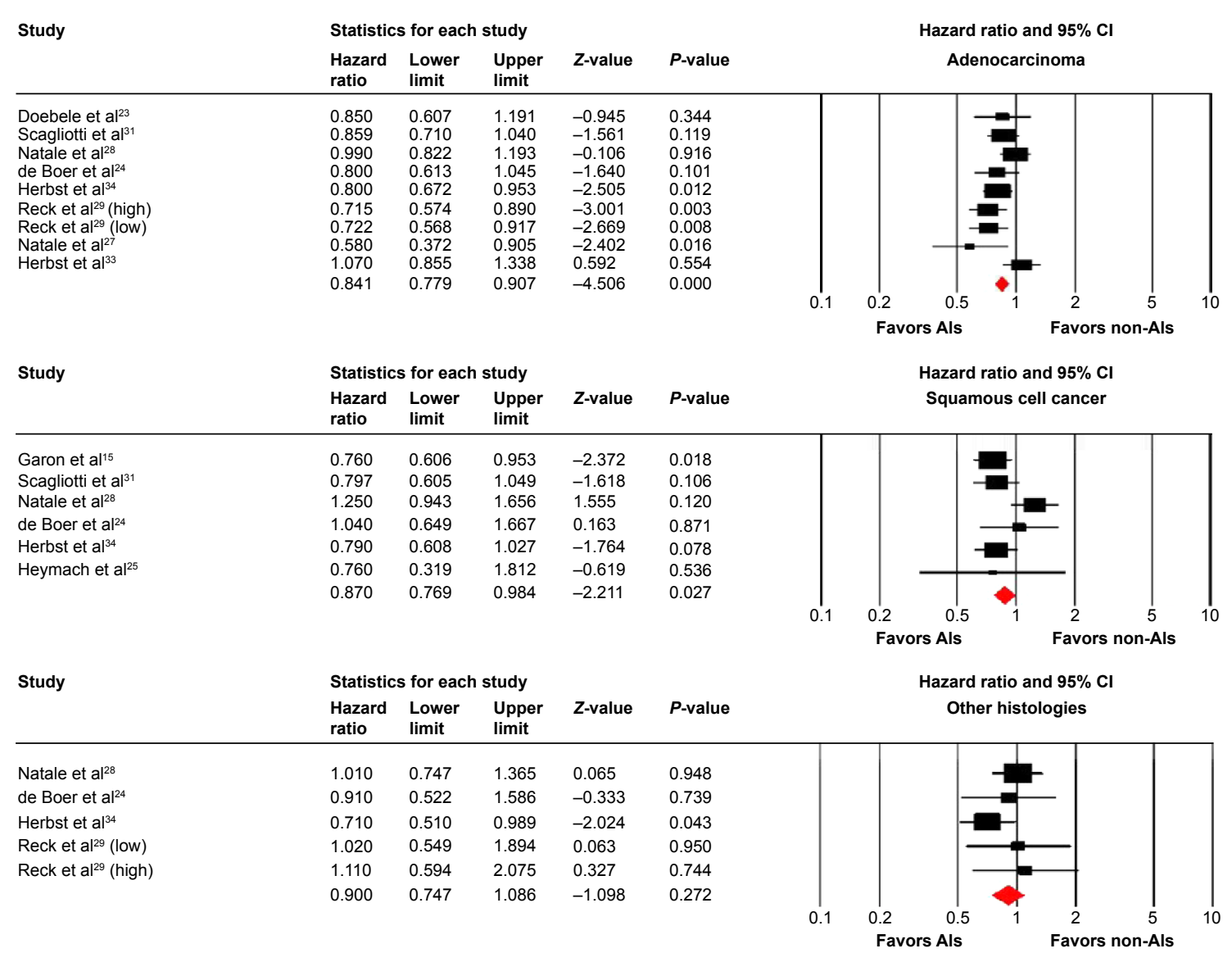

Figure 3 Fixed-effects model of $\mathrm{HR}(95 \% \mathrm{Cl})$ of PFS associated with Al-containing regimens versus non-Al-containing regimens.

Abbreviations: $\mathrm{HR}$, hazard ratio; $\mathrm{Cl}$, confidence interval; OS, overall survival; Als, angiogenesis inhibitors; PFS, progression-free survival.

there is a tendency to improve OS and PFS in patients with other histologies receiving AI-containing regimens. Therefore, the current findings suggest that, in patients with lung adenocarcinoma, AI-containing regimens could be a preferable treatment option over standard chemotherapy alone, although this recommendation cannot be conclusive because the overall comparisons are not based on randomization. Furthermore, the efficacy of AIs in patients with other histological types still needs to be assessed due to limited patients included in this study.

Our analysis has some obvious limitations. First, all included studies are conducted at major academic institutions among patients with adequate major organ function; thus, the results may not entirely apply to the general patient population in the community or patients with organ dysfunction. Second, we included patients receiving different antiangiogenesis agents for analysis. While each of these molecules inhibits angiogenesis, these drugs have different potencies, and have inhibitory properties against a range of nonoverlapping targeted receptors. Given the limited sample size of patients treated with any single AI, we decide to include patients treated with all of these drugs in this class with adequate data on survival of patients with NSCLC according to histologies, which would increase the clinical heterogeneity among included trials. Third, the toxicity profile is another important factor for choosing treatment options. However, it is not possible to perform an analysis to deal with such a concern because reports of adverse events from each subgroup are not available. Finally, in the meta-analysis of published studies, publication bias is important because trials with positive results are more likely to be published and trials with null results tend not to be published. Our research detects no publication bias for OS, but not for PFS.

\section{Conclusion}

In conclusion, this is the first meta-analysis specifically assessing the role of AIs in advanced NSCLC according to histological types. The results of our study suggest that the addition of AIs to the treatment therapies for patients with lung adenocarcinoma offers an improved survival benefit when compared to non-AI-containing regimens. Prospective 
clinical trials investigating the role of AIs in this setting are recommended.

\section{Funding}

Supported by Science and Technology Planning Project of Guangdong Province, People's Republic of China (2009 B030801011) and Guangdong medical science research fund (B2012194, B2011100).

\section{Disclosure}

The authors report no conflicts of interest in this work.

\section{References}

1. Jemal A, Bray F, Center MM, Ferlay J, Ward E, Forman D. Global cancer statistics. CA Cancer J Clin. 2011;61(2):69-90.

2. NSCLC Meta-Analyses Collaborative Group. Chemotherapy in addition to supportive care improves survival in advanced non-small-cell lung cancer: a systematic review and meta-analysis of individual patient data from 16 randomized controlled trials. J Clin Oncol. 2008; 26(28):4617-4625.

3. Qi WX, Wang Q, Jiang YL, et al. Overall survival benefits for combining targeted therapy as second-line treatment for advanced nonsmall-cell-lung cancer: a meta-analysis of published data. PLoS One. 2013;8(2):e55637.

4. Folkman J. Anti-angiogenesis: new concept for therapy of solid tumors. Ann Surg. 1972;175(3):409-416.

5. Claesson-Welsh L, Welsh M. VEGFA and tumour angiogenesis. J Intern Med. 2013;273(2):114-127.

6. Carmeliet P, Jain RK. Angiogenesis in cancer and other diseases. Nature. 2000;407(6801):249-257.

7. Ferrara N, Gerber HP, LeCouter J. The biology of VEGF and its receptors. Nat Med. 2003;9(6):669-676.

8. Lauro S, Onesti CE, Righini R, Marchetti P. The use of bevacizumab in non-small cell lung cancer: an update. Anticancer Res. 2014;34(4): $1537-1545$.

9. Soria JC, Mauguen A, Reck M, et al. Systematic review and metaanalysis of randomised, phase II/III trials adding bevacizumab to platinum-based chemotherapy as first-line treatment in patients with advanced non-small-cell lung cancer. Ann Oncol. 2013;24(1):20-30.

10. Sandler A, Gray R, Perry MC, et al. Paclitaxel-carboplatin alone or with bevacizumab for non-small-cell lung cancer. $N$ Engl $J$ Med. 2006;355(24):2542-2550.

11. Qi WX, Tang LN, He AN, Shen Z, Yao Y. The role of vandetanib in the second-line treatment for advanced non-small-cell-lung cancer: a meta-analysis of four randomized controlled trials. Lung. 2011; 189(6):437-443.

12. Belani CP, Yamamoto N, Bondarenko IM, et al. Randomized phase II study of pemetrexed/cisplatin with or without axitinib for non-squamous non-small-cell lung cancer. BMC Cancer. 2014;14:290.

13. Reck M, Kaiser R, Mellemgaard A, et al. Docetaxel plus nintedanib versus docetaxel plus placebo in patients with previously treated non-small-cell lung cancer (LUME-Lung 1): a phase 3, double-blind, randomised controlled trial. Lancet Oncol. 2014;15(2):143-155.

14. Scagliotti GV, Felip E, Besse B, et al. An open-label, multicenter, randomized, phase ii study of pazopanib in combination with pemetrexed in first-line treatment of patients with advanced-stage non-small-cell lung cancer. J Thorac Oncol. 2013;8(12):1529-1537.

15. Garon EB, Ciuleanu TE, Arrieta O, et al. Ramucirumab plus docetaxel versus placebo plus docetaxel for second-line treatment of stage IV non-small-cell lung cancer after disease progression on platinum-based therapy (REVEL): a multicentre, double-blind, randomised phase 3 trial. Lancet. 2014;384(9944):665-673.
16. Dy GK, Hillman SL, Rowland KM Jr, et al. A front-line window of opportunity phase 2 study of sorafenib in patients with advanced nonsmall cell lung cancer: North Central Cancer Treatment Group Study N0326. Cancer. 2010;116(24):5686-5693.

17. Arnold AM, Seymour L, Smylie M, et al. Phase II study of vandetanib or placebo in small-cell lung cancer patients after complete or partial response to induction chemotherapy with or without radiation therapy: National Cancer Institute of Canada Clinical Trials Group Study BR.20. J Clin Oncol. 2007;25(27):4278-4284.

18. Hong S, Tan M, Wang S, Luo S, Chen Y, Zhang L. Efficacy and safety of angiogenesis inhibitors in advanced non-small cell lung cancer: a systematic review and meta-analysis. J Cancer Res Clin Oncol. 2015; 141(5):909-921.

19. Moher D, Liberati A, Tetzlaff J, Altman DG. Preferred reporting items for systematic reviews and meta-analyses: the PRISMA statement. PLoS Med. 2009;6:e1000097.

20. Moher D, Pham B, Jones A, et al. Does quality of reports of randomised trials affect estimates of intervention efficacy reported in meta-analyses? Lancet. 1998;352(9128):609-613.

21. Zintzaras E, Ioannidis JP. Heterogeneity testing in meta-analysis of genome searches. Genet Epidemiol. 2005;28(2):123-137.

22. Vandenbroucke JP. Bias in meta-analysis detected by a simple, graphical test. Experts' views are still needed. BMJ. 1998;316(7129):469-470; author reply 70-71.

23. Doebele RC, Spigel D, Tehfe M, et al. Phase 2, randomized, openlabel study of ramucirumab in combination with first-line pemetrexed and platinum chemotherapy in patients with nonsquamous, advanced/ metastatic non-small cell lung cancer. Cancer. 2015;121(6):883-892.

24. de Boer RH, Arrieta $\mathrm{O}$, Yang $\mathrm{CH}$, et al. Vandetanib plus pemetrexed for the second-line treatment of advanced non-small-cell lung cancer: a randomized, double-blind phase III trial. J Clin Oncol. 2011;29(8): 1067-1074.

25. Heymach JV, Paz-Ares L, De Braud F, et al. Randomized phase II study of vandetanib alone or with paclitaxel and carboplatin as firstline treatment for advanced non-small-cell lung cancer. J Clin Oncol. 2008;26(33):5407-5415.

26. Hoang T, Dahlberg SE, Schiller JH, et al. Randomized phase III study of thoracic radiation in combination with paclitaxel and carboplatin with or without thalidomide in patients with stage III non-small-cell lung cancer: the ECOG 3598 study. J Clin Oncol. 2012;30(6):616-622.

27. Natale RB, Bodkin D, Govindan R, et al. Vandetanib versus gefitinib in patients with advanced non-small-cell lung cancer: results from a two-part, double-blind, randomized phase ii study. J Clin Oncol. 2009;27(15):2523-2529.

28. Natale RB, Thongprasert S, Greco FA, et al. Phase III trial of vandetanib compared with erlotinib in patients with previously treated advanced non-small-cell lung cancer. J Clin Oncol. 2011;29(8):1059-1066.

29. Reck M, von Pawel J, Zatloukal P, et al. Phase III trial of cisplatin plus gemcitabine with either placebo or bevacizumab as first-line therapy for nonsquamous non-small-cell lung cancer: AVAil. J Clin Oncol. 2009;27(8):1227-1234.

30. Scagliotti G, Novello S, von Pawel J, et al. Phase III study of carboplatin and paclitaxel alone or with sorafenib in advanced non-small-cell lung cancer. J Clin Oncol. 2010;28(11):1835-1842.

31. Scagliotti GV, Krzakowski M, Szczesna A, et al. Sunitinib plus erlotinib versus placebo plus erlotinib in patients with previously treated advanced non-small-cell lung cancer: a phase III trial. J Clin Oncol. 2012;30(17):2070-2078.

32. Scagliotti GV, Vynnychenko I, Park K, et al. International, randomized, placebo-controlled, double-blind phase III study of motesanib plus carboplatin/paclitaxel in patients with advanced nonsquamous non-smallcell lung cancer: MONET1. J Clin Oncol. 2012;30(23):2829-2836.

33. Herbst RS, Ansari R, Bustin F, et al. Efficacy of bevacizumab plus erlotinib versus erlotinib alone in advanced non-small-cell lung cancer after failure of standard first-line chemotherapy (BeTa): a doubleblind, placebo-controlled, phase 3 trial. Lancet. 2011;377(9780): 1846-1854. 
34. Herbst RS, Sun Y, Eberhardt WE, et al. Vandetanib plus docetaxel versus docetaxel as second-line treatment for patients with advanced non-small-cell lung cancer (ZODIAC): a double-blind, randomised, phase 3 trial. Lancet Oncol. 2010;11(7):619-626.

35. Sterne JA, Gavaghan D, Egger M. Publication and related bias in metaanalysis: power of statistical tests and prevalence in the literature. J Clin Epidemiol. 2000;53(11):1119-1129.

36. Kato H, Ichinose Y, Ohta M, et al. A randomized trial of adjuvant chemotherapy with uracil-tegafur for adenocarcinoma of the lung. $N$ Engl J Med. 2004;350(17):1713-1721.
37. Nakagawa M, Tanaka F, Tsubota N, et al. A randomized phase III trial of adjuvant chemotherapy with UFT for completely resected pathological stage I non-small-cell lung cancer: the West Japan Study Group for Lung Cancer Surgery (WJSG) - the 4th study. Ann Oncol. 2005;16(1):75-80.

\section{Publish your work in this journal}

OncoTargets and Therapy is an international, peer-reviewed, open access journal focusing on the pathological basis of all cancers, potential targets for therapy and treatment protocols employed to improve the management of cancer patients. The journal also focuses on the impact of management programs and new therapeutic agents and protocols on

\section{Dovepress}

patient perspectives such as quality of life, adherence and satisfaction. The manuscript management system is completely online and includes a very quick and fair peer-review system, which is all easy to use. Visit http://www.dovepress.com/testimonials.php to read real quotes from published authors. 